\title{
BUILDING SOCIAL CAPITAL THROUGH INCLUSIVE BASKETBALL
}

\author{
S. Djobova*, M. Borukova, I. Kirilova \\ National Sports Academy "Vassil Levski”, Sofia, Bulgaria
}

\begin{abstract}
The inclusive basketball program of the National Sports Academy is a compilation of adapted and unified basketball where persons with intellectual and physical disabilities together with students and volunteers are training and competing together.

PURPOSE of this study is to explore the extent of contribution of our program for the building of social capital. The concept of social capital is drawn from psychology, sociology and economy. It is defined as controversial due to many theories and cultural diversity behind.

METHODS: Participants in the study were all persons involved in the adapted basketball program. Data was collected using interviews, life-story techniques, field notes and tests batteries for basketball skills. RESULTS are showing improvement in personal development domain for the athletes with disabilities where sport specific skills, building trust and communications were the leading components. For the students in the same domain the leading components of improvement were attitudes and relationships. Positive change was found in the domains of social inclusion, micro-culture and participation. We also found that there is direct and indirect production of social capital.

CONCLUSION: inclusive sport practice like our adapted basketball program could be considered as a powerful contributor to the building of social capital.
\end{abstract}

Key words: inclusion, unified sport, socialization, skills, Special Olympics

\section{INTRODUCTION}

Sport has the universal power to unite people, to overcome political, cultural, and social barriers, and to develop a human personality. Participation to sport is a basic human right but still many persons with disabilities limited or no access to sport. Some existing opportunities are segregated and exclusive. Inclusive sports are practices that encompass diverse physical activities and sports training where persons with and without disabilities are enjoying sport under the environment of equity. Sport opportunities for persons with disabilities can differ along a number of structural aspects including the amount of segregation or integration of disabled and able-bodied athletes or of athletes with different types or degrees of disability within a mainstream sport, degree of

\footnotetext{
*Correspondence to: Stefka Djobova, National Sports Academy "Vassil Levski", Faculty of Public health, health care and tourism, Water sports department, sector Adapted physical activity and sport; Faculty of Pedagogy, Basketball, volleyball, handball department, sector Basketball, 1700, Sofia, Studentski grad, Email:

Stefka.djobova@abv.bg, Mobile: +359893 396331
}

adaptation, classifications, level of competitive intensity and inclusiveness of eligibility. Two prominent examples of disability sport are the Special Olympics and the Paralympics.

The scientific research of social and cultural aspects of disability sport is relatively new. The first attempt to collect academic work in this area was done by Claudine Sherrill as editor in the distant 1986 in a book named Social and psychological dimensions of sport for disabled athletes (1). The first comprehensive book about sport for persons with disabilities - "Disability and Sport", was published in 1995 by DePauw and Gavron (2). The two leading journals publishing studies of disability sport are the Adapted Physical Activity Quarterly and European Journal in Adapted Physical Activity. Ian Brittain has researched social aspects of disability sport also. According to Bailey (3),+ participation in sport supports the development of social capital by emphasizing on social activity, like an opportunity to make friendships, establishing networks and decrease social segregation. The position of Chandler et al. is 
that sports participation can influence the social policy and is defined as an important part of the campaign for better social inclusion. Instinctively there is an acceptance that sport, as a hypothetically friendly and positive activity can be used to integrate omitted groups into general society (4).

Social Capital is a frequently used commodity within social relations and an ever-developing concept. (5). It has arisen as a significant concept in policy, academic and sport debates in recent years. The concept wildly varies between different social capital theories. In the sociological literature, Coleman is defining it as all those features of the social structure that might facilitate the actions of individuals within the social structure itself (6). According to Bourdieu social capital is the aggregate of the actual or potential social relation which is linked to possession of a durable network of more or less institutionalized relationships of mutual acquaintance and recognition (7). Another definition states that "Social capital is taken to refer to social networks based on social and group norms which enable people to trust and cooperate with each other and through which individuals or groups can obtain certain types of advantage" (8). The political scientist Robert Putnam describes social capital as those features of social life, such as networks, trust and norms, and that allow participants to act together to pursue shared objectives, in other words to improve the efficiency of society by facilitating coordinated actions (9). Many authors determine the aforementioned definition as the most popular. The adopted definition from the World Bank of social capital is: "Social capital is not just the sum of the institutions which underpin a society - it is the glue that holds them together" (10). It is fairly near to that of Putnam et al (9). We assumed the World Health Organizations purpose for definition as a quite basic - "social capital represents the degree of social cohesion which exists in communities" (11). Analyzing this definition, we can conclude that Social capital can be seen as a way to broaden the empowerment process, community development and well-being.

This review of definitions is given to visualized direct or indirect relation to social connections or social networks as elements of social capital. For the purpose of our study, we find closer and adopt the Putman definition because it points to the role of social capital as a catalyst of cooperation, an essential device to achieve better social outcomes. In addition, we also recognize the limitation of Social capital as a concept due to many theories and cultural diversity behind.

At the same time, there is increasing recognition of the potential role of social capital and networks in community development, both for understanding it conceptually and for strengthening practice as in sport.

Our literature review found that the research on sport and social capital is rare, discussions are fragmented due to diversity in definitions and the role of sport as a social capital contributor as well the forms that are generated in the domain of sport.

Traditionally the sport development programs especially those delivered at the community level are defined as a generator of social capital. More recently, the positive impact of participation in sport and active recreation on physical health and personal development are well accepted as a contributor of social capital. The promotion of social inclusion through sports has received increased attention with other disadvantaged groups, this is not the case for children and adults with intellectual disability who experience marked social isolation (12).

The contribution of sport to the creation of social capital and the countering of social exclusion is highlighted by the capacity of sport to bring groups of people together that might ordinarily remain apart. Marginalized groups, such as young people with intellectual disabilities, may engage, or be encouraged to engage in sporting disciplines alongside and against non-disabled partners with the express aim of promoting social integration (13). Special Olympics (SO) in general and its most successful program Unified sports in particular is defined as a world leader in the promotion of social inclusion through sport (14). Special Olympics Unified Sports ${ }^{\circledR}$ (SOUS) brings together athletes with and without intellectual disabilities (ID) to train and compete on the same team. Throughout the year, in a variety of sports ranging from basketball to golf to figure skating, Unified Sports athletes improve their physical fitness, sharpen their skills, challenge the competition and have fun, too. The concept of combining athletes with ID and those without (called partners) was first introduced 
in the United States in the mid-1980s to provide another level of challenge for higher ability athletes and to promote equality and inclusion (15). The program enables athletes to learn new sports, develop higher-level sports skills, and have new competition experiences, experience meaningful inclusion as each athlete is ensured of playing a valued role on the team. As SO reported the program provides an opportunity for positive social interaction between teammates and often leads to long-lasting friendships (15). Unified Sports programs frequently are initiated by community partners, including parks and recreation departments, schools, municipality events community sports organizations. These partnerships facilitate the inclusion process of participation of athletes with ID in their community and gives choices outside of Special Olympics circumstance. According to McConkey et al. (12) Unified Sports is a vehicle for promoting the social inclusion of people with intellectual disabilities that is theoretically credible in terms of social capital scholarship and which contains lessons for advancing social inclusion in other contexts. Bringing together athletes with and without intellectual disabilities to train and compete together is a powerful tool for inclusion (16). Dowling et al. reported that the aforementioned program "is in essence a fairly simple idea, providing, as it does, a forum for young people with intellectual disabilities to connect with their wider community and meet with other young people around a shared interest in sports". According to their study the program functions using a "complex dynamic of connections at three levels - the people participating in the program, the organization underlying it and the interaction with the local community which three are interactive and mutually transforming (13).

Basketball is one of the most popular sports of Special Olympics. With the support of the International Basketball Federation (FIBA), so basketball events are flourishing and have been reaching vast popularity in the recent years. This sport combines together players of all ages and abilities, from total beginners learning to handle the ball and keep it under control while dribbling to more experienced players who have the moves and know the strategies to play challenging balls. (14).

Inspired by the Unified basketball good practices around the world at the beginning of
2019 , we took the initiative to establish new sport opportunity for people with intellectual disabilities. Basketball Sector at the "Basketball, Volleyball and Handball" Department, Adapted Physical Activity and Sports Sector at the "Water Sports" Department and Special Olympics Bulgaria launched an inclusive trainings in adapted basketball at National Sports Academy (NSA) "Vassil Levski". Training sessions are attended by athletes with intellectual disabilities (Special Olympics Bulgaria athletes) and their sports partners - basketball and adapted physical activity students and at the NSA. The provision of sustainable basketball programs for people with intellectual disabilities is still very limited in Bulgaria. As the program is pretty new the number of athletes joining is slight, but what is more difficult is to attract partners. This practice is the first of its type for our country and it is organized on the model of Special Olympics Unified sports.

The aim of this study is to explore the extent of contribution of our inclusive basketball program to the building of social capital.

\section{METHODS}

The study is covering a period of sixteen months. Participants were all persons involved in the adapted basketball program including eighteen athletes with intellectual disabilities, twelve graduate students from basketball and Adapted physical activity specializations from the National Sports Academy, three coaches, five volunteers, twenty-two parents, and two personal assistants of the athletes which are referred further also as parents, three senior officials from Special Olympics Bulgaria.

Qualitative data was gathered using interviews, life-story techniques, field notes. The specific sport skills development was evaluated using test batteries for basketball skills.

All participates were informed about the aim and procedures and all signed consent of agreement.

Connection charts, which mapped the range and extent of an individual's social network and personal development charts were also created.

\section{RESULTS}

Although Unified sports is described as a relatively simple idea which brings together persons with and without disabilities led by a common interest in playing a sport we have 
DJOBOVA S., et al.

found that actually it operates and covers different domains of interaction and have multifarious pathways of contribution to the building of social capital. We explore it mainly in two domains - individual development of human capital and community development through creation of inclusive environment.
Similar to the global report "Unified give us a chance" (10) we also found significant contribution of our program to the domain of personal development for both athletes with ID and their sporting partners. Personal benefits for the athletes are presented on Figure 1.

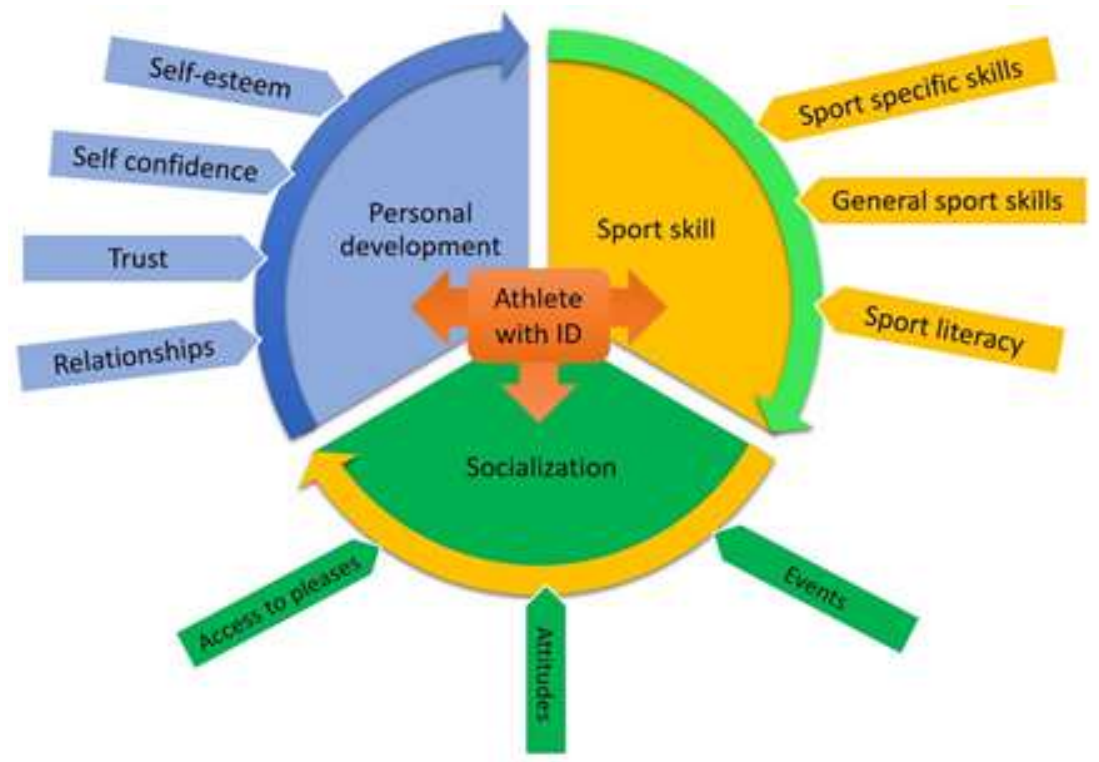

Figure 1. Spectrum of athlete development.

Through the report of the athletes, parents' opinion and our field notes we found improvement in three domains. The most significant is the development in sport skills including specific basketball skills, general sport skills including physical fitness and sport literacy. As improvement in sport, skills are widely reported in previous studies we are the first to consider the sport literacy item. We observed and parents confirmed improvement in self-esteem and self-confidence of the athlete. Their ability to quickly trust and establish relationships with new people were also enhanced. Through relationships athletes develop new skills for individual and group communication. Thanks to the participation in the program, athletes were introduced to new opportunities to attend events, both sport and social. They receive number of possibilities to access new places including sport facilities, public institution and media. Athletes also changed positively their attitudes toward physical activity, eating habits and personal care. The same positive changes were reported and observed within the partners. We discover new dimensions for their personal development. They exceed their role of sport partners and became leaders, coaches, health cancelers, friends and parents consultants (Figure 2).

We explain this with the fact that partners in our program are highly qualified university sport students who will become future coaches. They gain professional development because they practice with and learn from the athletes. Their maturation allows them to take additional roles and to be partners not only to the athletes but also to their parents as consultants. Our partners take successfully the role of leaders. They apply very often individual approach, they develop in addition individual sport training prescriptions and initiate out of training activities and interaction with the athletes and their parents. Unusual to other Unified sport programs is also the role of the three coaches. All of them university lecturers they combine competences in basketball training, disability sport and condition training. They are leading the training process but they also emphasize on the constant challenge of the partners. In their understanding, the stronger focus on the partners could lead to future development and sustainability of this pilot activity. Partners report a change in attitude toward coaching athletes with ID mainly due to the gained experience and specific upgrade of their coaching skills and knowledge. In addition to that, some of the partners are high-level basketball players who will further serve as ambassadors of Unified basketball. 


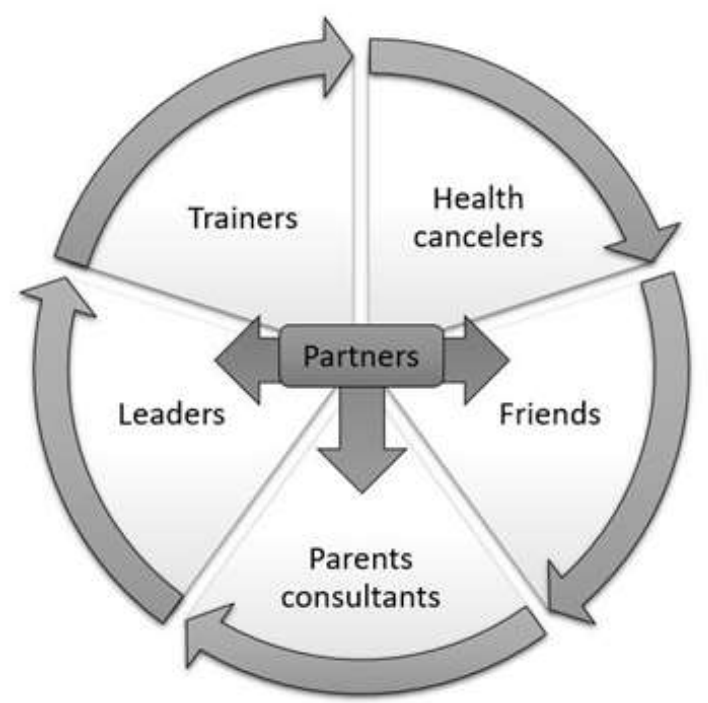

Figure 2. Partner's development.

Positive changes are also found among the parents. This notion is based on their selfreports. Parents demonstrated increased understanding of their children. This is partly demonstrated through the degree of freedom and trust given to their children. Parents became more open, communicative and relaxed in their daily routine through the exchange of experiences with the others. They report increased awareness of disability health issues and general functioning gained inside the newly created community. All these findings are considered the way of direct contribution to the social capital.

Indirect contribution to the social capital is seen in the creation of inclusive environment that covers large range of applications shown on Figure 3.

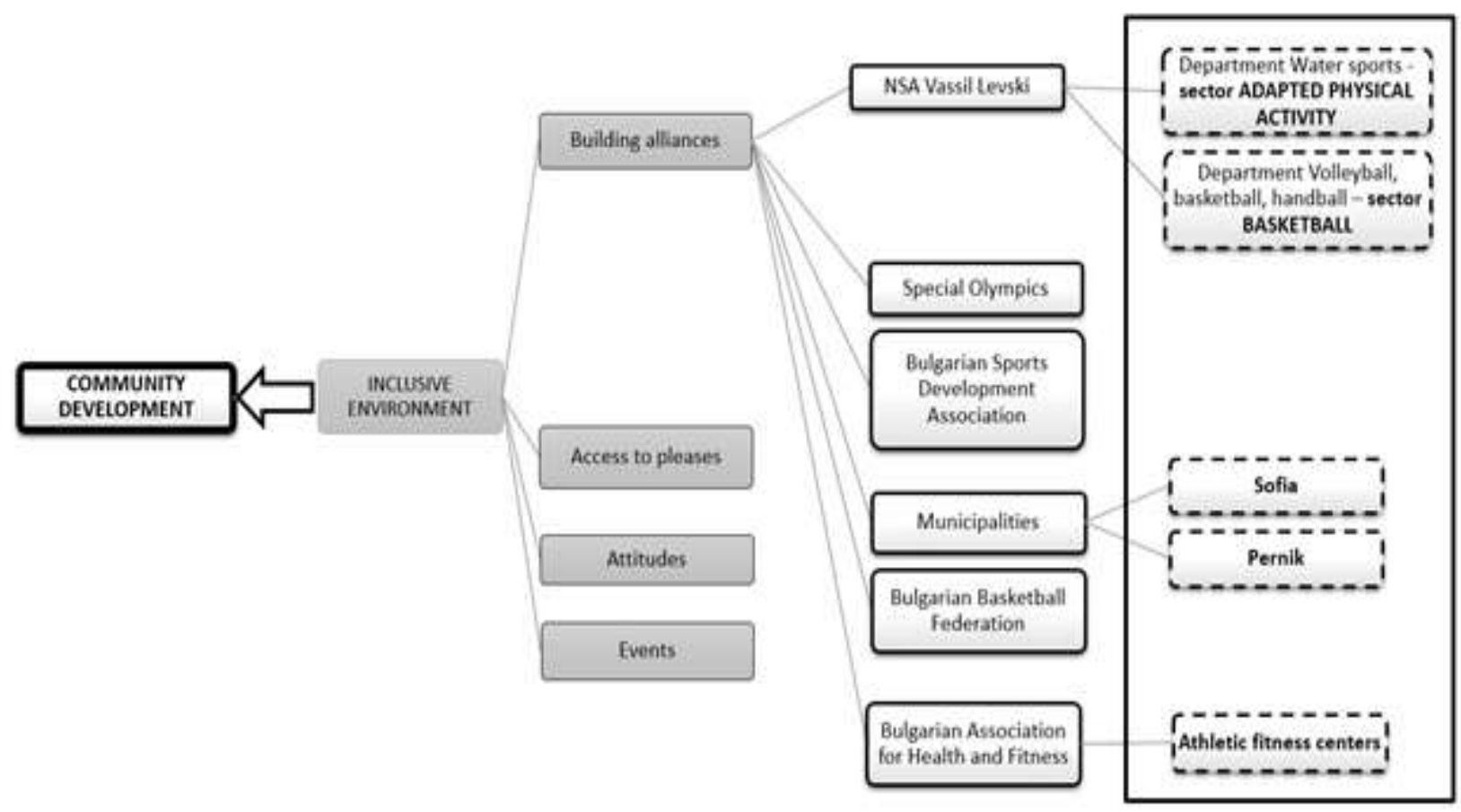

Figure 3. Indirect contribution to the social capital

The most important result for us is the creation of multiple stakeholders alliance. Different departments of the NSA united their diverse expertise to respond to the society demands for the creation of sport opportunities for persons with disabilities. The NSA is placed in the center of the network with key stakeholders from the non-governmental sector like Special Olympics Bulgaria, Bulgarian Sport Development Association, Bulgarian Basketball Federation and Bulgarian Association for Health and Fitness. Thanks to 
our program this organizations began cooperation and supported us by provision of additional opportunity for fitness training, access to events and creation of competition opportunities, engagement with popularization and additional health and well-being coaching. Just for one year two municipalities became more engaged with concept of inclusive sport events where persons with ID are seen as active participants. This is a giant leap because traditionally persons with disabilities are considered eventually only as observers in community sport events.

\section{CONCLUSION}

Traditionally building social capital through sport is viewed form the development work and social responsibility of the sport clubs (10). We present innovation initiated by academic establishment for the benefits of two groups - future coaches and persons with intellectual disabilities.

We also confirm a previous finding that are difficult to quantify how participation in sport and physical recreation contributes to, develops or maintain social capital, but at the same time, we discovered new contributors to that. Other authors claim that it is not possible to observe the extent to which the existence of social capital promotes participation in sport. We agree partly with that because our results are showing that once established the program could reach level of independent existence and continuous self-development. This is the result of social processes that cannot be accurately measured but could be evaluated through the impact they provoke and the range of social indicators that may be used to assess social capital and wellbeing.

\section{REFERENCES}

1. Sherrill, C., ed. Sport and disabled athletes. Champaign, IL. Human Kinetics 1986.

2. DePauw, K., Gavron, P., S. J. Disability and Sport. Human Kinetics, Champaign, IL. 1995.

3. Bailey, R., ed. Youth sport and social inclusion, in Holt, N.L. Positive Youth Developments through Sport. Routledge: Oxford 2008.
4. Chandler, T., Cronin, M., and Vamplew, W., Sport and Physical Education: The Key Concepts. Routledge: New York 2007.

5. Skinner, J., Zakus, D., Cowell, J., Development through Sport: Building Social Capital in Disadvantaged Communities Sport Management Review Volume 11, Issue 3, November 2008.

6. Coleman, J., Social capital in the creation of human capital. American Journal of Sociology, 94 (Suppl) :S95-S120, 1988.

7. Bourdieu, P., The forms of capital. In: Halsey A.H., Lauder H., Brown P., Wells A.M., editors. Education, Culture, and Society. Oxford University Press; Oxford, UK:1997.

8. Coalter, F., Sports clubs, social capital and social regeneration: 'ill-defined interventions with hard to follow outcomes'? Sport in Society, 10, 2007.

9. Putnam, RD., Leonardi, R., Nanenetti, R., Making democracy work: civic traditions in modern Italy. Princeton, NJ. Princeton University Press. 1993.

10.World Bank, The Changing Wealth of Nations. Washington DC: The World Bank. 2011.

11.Rocco, L., Suhrcke, M., Is social capital good for health? A European perspective. Copenhagen, WHO Regional Office for Europe, 2012.

12.McConkey, R., Dowling, S., Hassan, D., Menke, S., Promoting social inclusion through Unified Sports for youth with intellectual disabilities: a five-nation study 2010.

13.Dowling, S., McConkey, R., Hassan, D., Menke, S., Unified gives us a chance' An evaluation of Special Olympics Youth Unified Sports ${ }^{\circledR} \quad$ Programme in Europe/Eurasia 2010.

14.Borukova, M., Djobova, S., Kirilova, I., Assessing Special Olympics athlete's skills and forming unified basketball team, Annual of the NSA Vassil Levski Volume 1, Sofia, 2020.

15.Special Olympics handbook, Unified sports, 2003.

16.Djobova, S., Theoretical and applied aspects of sport for persons with disabilities. Sofia: Bolid-INS, 2018. 